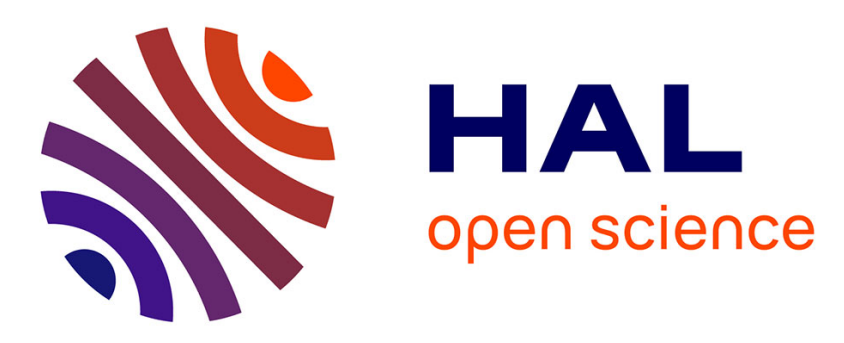

\title{
Sub-10 nm electron and helium ion beam lithography using a recently developed alumina resist
}

Andrea Cattoni, Dominique Mailly, Olivier Dalstein, Marco Faustini, Gediminas Seniutinas, Benedikt Rösner, Christian David

\section{To cite this version:}

Andrea Cattoni, Dominique Mailly, Olivier Dalstein, Marco Faustini, Gediminas Seniutinas, et al.. Sub-10 nm electron and helium ion beam lithography using a recently developed alumina resist. Microelectronic Engineering, 2018, 193, pp.18-22. 10.1016/j.mee.2018.02.015 . hal-01723319

\section{HAL Id: hal-01723319 https://hal.sorbonne-universite.fr/hal-01723319}

Submitted on 5 Mar 2018

HAL is a multi-disciplinary open access archive for the deposit and dissemination of scientific research documents, whether they are published or not. The documents may come from teaching and research institutions in France or abroad, or from public or private research centers.
L'archive ouverte pluridisciplinaire HAL, est destinée au dépôt et à la diffusion de documents scientifiques de niveau recherche, publiés ou non, émanant des établissements d'enseignement et de recherche français ou étrangers, des laboratoires publics ou privés. 


\title{
Sub-10 nm Electron and Helium Ion Beam Lithography Using a Recently Developed Alumina Resist
}

Andrea Cattoni $^{\mathrm{a}}$, Dominique Mailly ${ }^{\mathrm{a}}$, Olivier Dalstein ${ }^{\mathrm{b}}$, Marco Faustini ${ }^{\mathrm{b}}$, Gediminas Seniutinas ${ }^{\mathrm{c}}$, Benedikt Rösner $^{\mathrm{c}}$, Christian David $^{\mathrm{c}}$

${ }^{a}$ Centre de Nanosciences et de Nanotechnologies (C2N) CNRS, Université Paris-Sud, Université Paris-Saclay, Marcoussis, 91460, France

${ }^{\mathrm{b}}$ Laboratoire de Chimie de la Matière Condensée de Paris, Collège de France, UPMC Sorbonne Université, Paris, 75252, France

${ }^{\mathrm{c}}$ Paul Scherrer Institut, 5232 Villigen PSI, Switzerland

Corresponding author: andrea.cattoni@,c2n.upsaclay.fr

Keywords: Electron Beam Lithography, Helium FIB, sol-gel based resist

\begin{abstract}
Electron beam lithography (EBL) at sub-10 nm resolution is mainly limited by resist contrast and proximity effects. In this work, we investigate the use of a recently developed alumina-based resist as a negative-tone resist for electron EBL at $100 \mathrm{keV}$ and focused helium ion beam lithography (FHIBL). The resist is synthesized using a sol-gel method and turns into a near completely inorganic alumina system when exposed to the electron/ion beam. We first investigate the effect on the resist contrast curve on i) development temperature; ii) stability of the resist after exposure and before post-baking and development; and iii) aging of the resist solution. We demonstrate the patterning of isolated features as small as $6.5 \mathrm{~nm}$ using an EBL and $5 \mathrm{~nm}$ using FHIBL and a resolution down to $10 \mathrm{~nm}$ for FHIB exposed films. Finally, we demonstrate the pattern transfer of $10 \mathrm{~nm}$ lines with an aspect ratio of 10 in silicon, using an optimized reactive ion etching process.
\end{abstract}

\section{Introduction}

Electron Beam Lithography (EBL) at sub-10 nm resolution is mainly limited by resist contrast and the point-spread function of the exposing beam. In the case of high-resolution silsesquioxane (HSQ) negative-tone resist, much work was devoted to improving the contrast of the development process using hot development, ${ }^{1,2,3,4} \mathrm{KOH}$ development, ${ }^{5,6}$ or salty development. ${ }^{7}$ Some authors have addressed the problem using focused helium-ion beam lithography (FHIBL), which features smaller proximity effects as compared to an electron beam at the same incident kinetic energy., ${ }^{8,9,10}$ In addition to improved resolution and line edge roughness, the development of new EBL resists has also been triggered by the need of high sensitivities resists ${ }^{11}$ and environmental benign development processes. ${ }^{12}$ Despite the high resolution demonstrated using these approaches, the problem of pattern transfer is rarely addressed and remains problematic a this scale, mainly due to the relatively low plasma etching resistance of HSQ or polymeric resists for fluorinated plasmas used in silicon dry etching.

Recently, the group of Brusantin developed a hybrid organic-inorganic alumina-based resist for electron- or photonbased nanolithography. ${ }^{13}$ The resist is synthesized using a sol-gel method and turns into an almost completely inorganic alumina system when exposed to the electron beam. The modification of the organic component of the exposed areas leads to the possibility of developing the resist as a negative-tone resist dissolving the organic unexposed part in hydrochloric acid ( $\mathrm{HCl})$ : isopropyl alcohol (IPA) solution or as a positive-tone resist dissolving the inorganic exposed part in buffered oxide etch (BOE). Used as negative-tone resist for EBL (at $3 \mathrm{keV}$ ) the authors of the study demonstrated isolated features down to $11 \mathrm{~nm}$ and an exceptional selectivity (100:1) when used as a mask for inductively coupled plasma (ICP) etching of silicon in fluorinated plasmas. ${ }^{14}$

In this work - performed within the framework of the EU project NFFA-Europe (Nanoscience Foundries and Fine Analysis), the H2020 framework program for research and innovation, and grant agreement 654360 - we explore the possibility to use such an alumina-based resist for sub-10 nm patterning of silicon. The resist is used as a negative-tone resist and exposed using an EBL system at $100 \mathrm{keV}$ as well as a FHIBL system at $30 \mathrm{keV}$. Pattern transfer in silicon was performed using a reactive ion etching (RIE) with a relatively low bias in order to improve the selectivity. The results of this work will be used in the Transnational Access program within the NFFA-Europe project to provide access to ultra-high resolution patterning techniques.

\section{Materials and Methods}

The resist is synthesized using a sol-gel method starting with aluminum-tri-sec-butoxide (97\%, Aldrich) and triethoxyphenylsilane (98\%, Aldrich). Note that we replaced the trimethoxyphenylsilane used in the original publications $^{13,14}$ with the less toxic triethoxyphenylsilane. The aluminum-tri-sec-butoxide was left stirring $1 \mathrm{~h}$ at $70{ }^{\circ} \mathrm{C}$ in a solution of methoxyethanol and acetic acid in the molar ratio of 1:21:4.3. After $1 \mathrm{~h}$ the triethoxyphenylsilane was added in a molar ratio of 0.25 and the solution stirred for another hour at $70{ }^{\circ} \mathrm{C}$.

Silicon substrates were spin-coated at $5000 \mathrm{rpm}$ with the sol diluted in methoxyethanol with variable dilution to give adjusted film thicknesses of 35 and $20 \mathrm{~nm}$. The samples were pre-baked for 2 min at $100{ }^{\circ} \mathrm{C}$ in order to remove 
the residual solvent and exposed with an EBL system (VISTEC EBPG5000+) at $100 \mathrm{keV}$ and $250 \mathrm{pA}$ and a FHIBL system (ORION NanoFab from Zeiss) at $30 \mathrm{keV}$. Before development, the resist was typically post-baked at $120{ }^{\circ} \mathrm{C}$ for $2 \mathrm{~min}$, a temperature calibrated to increase the difference in inorganic condensation between exposed and un-exposed areas (SI in Grencia et al. ${ }^{14}$ ). It should be noted that the post-baking temperature optimization in ${ }^{14}$ was made on UVexposed resist while the optimized post-baking temperature for electron/ion-beam exposed resist may be different. The samples were developed in a $\mathrm{HCl}$ :IPA solution $(1 \div 2: 100)$ for a few minutes $(2 \div 5 \mathrm{~min})$ at room temperature $\left(21^{\circ} \mathrm{C}\right)$, rinsed in IPA for $1 \mathrm{~min}$ and dried under a nitrogen stream. Pattern transfer in silicon was carried out using a highly anisotropic reactive ion etching process based on $\mathrm{SF}_{6} / \mathrm{CHF}_{3}(1: 2)$ gasses and low bias (80V) obtained operating the RIE at a pressure of $15 \mathrm{mT}$ Torr and a relatively low power $(8 \mathrm{~W})$.

\section{Results \& Discussion}

Grencia et al. ${ }^{14}$ found that films spin-coated from the diluted solution were spoiled by the presence of pits when deposited in a clean room environment at relative humidity $(\mathrm{RH})$ of 50-60 \%, while much smoother films were obtained performing the spin-coating in a glove box at $\sim 100 \mathrm{ppm}$ relative humidity $(\mathrm{RH})$. We never observed such a problem, obtaining perfectly flat and defect-free spin-coated resist layers. The reason may be twofold: i) a lower relative humidity of our clean room ( $\mathrm{RH} 40 \%, 21{ }^{\circ} \mathrm{C}$ ) ii) a beneficial effect on spin-coating deposition of the resist synthesized with triethoxyphenylsilane, which has a different volatility compared to the trimethoxyphenylsilane used by the authors of the original study.

\subsection{Contrast curves}

Figure 1 shows a series of contrast curves measured in order to verify a certain number of post-baking and development combinations as well as to test the effect of aging the resist solution. First, we wanted to verify the influence of temperature development, notably at the developer temperature suggested by Grencia et al. ${ }^{14}\left(4^{\circ} \mathrm{C}\right)$ and at room temperature $\left(21^{\circ} \mathrm{C}\right)$.

a)

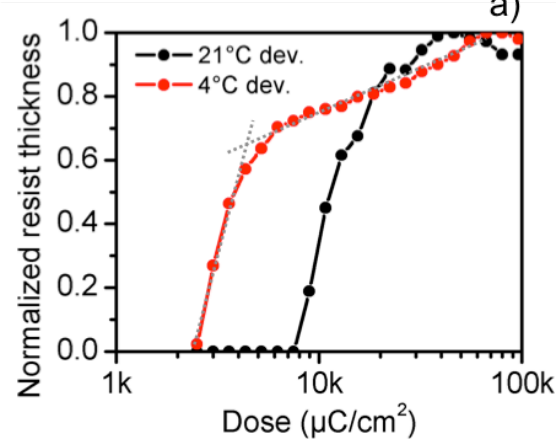

b)

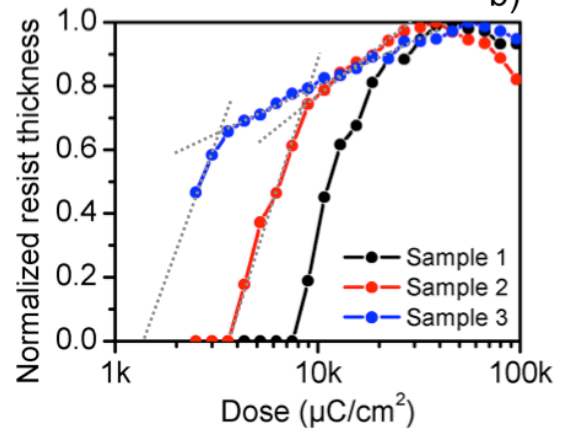

C)

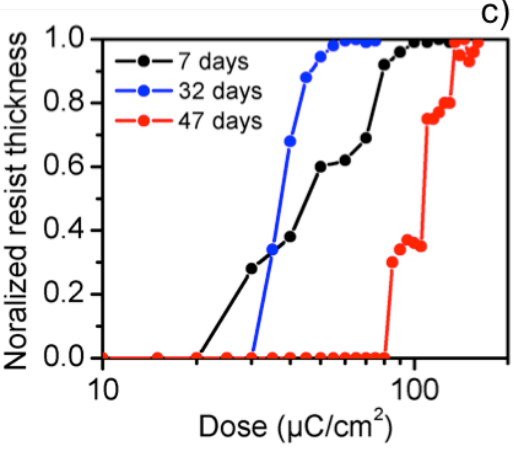

Figure 1 - a) Effect of the temperature development: EBL contrast curves of samples developed 5 min at $4{ }^{\circ} \mathrm{C}$ and $21^{\circ} \mathrm{C}$. b) Effect of the post-baking \& development delay: EBL contrast curves of Sample 1: post-backing and development after the exposure; Sample 2: post backing after exposure and development after $24 \mathrm{~h}$; Sample 3: post-backing and development after 24h from exposure. c) Effect of sol-gel solution aging: FHIB contrast curves of resist solution with different aging time.

Figure 1a) shows two contrast curves of a $35 \mathrm{~nm}$ thick resist exposed by EBL and developed in HCl:IPA (1:100) for 5 min at $4{ }^{\circ} \mathrm{C}$ and $21^{\circ} \mathrm{C}$. Low temperature development seems to increase the sensitivity of the resist while the contrast curve presents a double slope between $0-60 \%$ and between $60-100 \%$. The origin of this double slope in the contrast curve does not necessary originate from the low temperature development but may be related to surface modification of the resist when exposed to air for a certain amount of time before the development. In fact, the sample developed at $21^{\circ} \mathrm{C}$ was processed immediately after exposure while the sample developed at $4{ }^{\circ} \mathrm{C}$ was processed about 4 hours after exposure. In order to validate this hypothesis, we traced the EBL contrast curves for three different samples exposed at the same time but with different timing between exposure, post-baking and development. Reference Sample 1 (same curve of Figure $\left.1 \mathrm{a}, 21^{\circ} \mathrm{C}\right)$ was exposed and immediately post-baked $\left(2 \mathrm{~min}\right.$ at $\left.120^{\circ} \mathrm{C}\right)$ and developed $(5 \mathrm{~min}$ in $\mathrm{HCl}$ :IPA, 1:100 at $21^{\circ} \mathrm{C}$ ). Sample 2, was post-baked immediately after the exposure but developed after $24 \mathrm{~h}$. Sample 3 was postbaked and developed $24 \mathrm{~h}$ after exposure. During the $24 \mathrm{~h}$, Samples 2 and 3 were exposed to the clean room atmosphere $\left(\mathrm{RH} 40 \%, 21{ }^{\circ} \mathrm{C}\right)$. A delay in post-baking and development (Sample 3) results in higher resist sensitivity and the appearance of a double slope in the contrast curve (0-60\% and 60-100\%). A possible explanation may come from a modification of the resist from the surface (diffusion) when exposed to air. Note that the sol-gel precursor (aluminumtri-sec-butoxide) is extremely reactive in air, so the stability of the resist may not be assured even if all the solvents are evacuated through the pre-baking. A post-baking treatment performed after exposure (Sample 2) seems to partially 
stabilize the resist or at least limit surface modification (double slope between $0-70 \%$ and $70-100 \%$ ). Even though a post-baking treatment is performed immediately after the exposure, a $24 \mathrm{~h}$ delay in development results in increased resist sensitivity. For this reason, the change in resist sensitivity observed in Figure 1a should be partially ascribed to the delayed development experienced by the sample developed at $4{ }^{\circ} \mathrm{C}$ and further experiments should be carried out to separate the two contributions. Note that in all the cases of Figure $1 \mathrm{a}-\mathrm{b}$, the first contrast curve between $0-60 \div 70 \%-$ corresponding to a resist closer to the substrate and a priori not exposed to air - does not change significantly for the different process conditions.

Finally, we investigate the effect of solution aging on the contrast curve. Figure 1c shows three contrast curves using the same resist solution stored at room temperature for 7, 32, and 47 days from the preparation. The resist thickness was $35 \mathrm{~nm}$ and was exposed by FHIB and developed in HCl:IPA (1:100) for $5 \mathrm{~min}$ at $21^{\circ} \mathrm{C}$. Exposure with helium ions is more effective than electrons and results in higher sensitivity up to two orders of magnitude (resist used for contrast curves Figure 1a-b was aged 3-4 weeks). Interestingly, older solutions have a reduced sensitivity but feature an improved contrast. We attribute the staircase contrast curve for 47 days to a problem with the pattern generator of the FHIBL system.

\subsection{Electron and helium ion beam lithography}

Figure 2 shows a series of SEM images of alumina resist lines at different pitches ( $p=100,60,50$ and $40 \mathrm{~nm})$ exposed by EBL at $100 \mathrm{keV}$. Doses range from 35 to $80 \mathrm{mC} / \mathrm{cm}^{2}$ and beam step size (BSS) were adjusted in order to obtain the same line-width for the isolated line and the lines in the array. Lines with pitches $\mathrm{p}=100,60$ and $50 \mathrm{~nm}$ were exposed in a $35 \mathrm{~nm}$ thick resist and developed for $5 \mathrm{~min}$ at $21^{\circ} \mathrm{C}$ in $\mathrm{HCl}$ :IPA $(1: 100)$. Lines with pitch $\mathrm{p}=40 \mathrm{~nm}$ were exposed in a $20 \mathrm{~nm}$ thick resist and developed with the same solution and reduced time $(2 \mathrm{~min})$. For isolated $(\mathrm{p}=100 \mathrm{~nm})$ lines, proximity effects at $100 \mathrm{keV}$ are relatively small and sub-10 nm lines can be obtained (about 6,5 nm, Figure 2a-b) using a BSS of $1 \mathrm{~nm}$. At reduced line pitches of 60 and $50 \mathrm{~nm}$ (Figure 2c-d and e-f), it is still possible to obtain $10 \mathrm{~nm}$ and 20 $\mathrm{nm}$ lines by adjusting the BSS and the dose while preserving the same line-width for the isolated line and the lines in the array. In order to perfectly develop lines with pitch $\mathrm{p}=40 \mathrm{~nm}$ (Figure $2 \mathrm{~g}-\mathrm{f}$ ), we reduced the resist thickness down to $20 \mathrm{~nm}$. At this density, proximity effects start to be significant, giving a slightly thicker line-width for lines in the array $(15 \mathrm{~nm})$ compared to the isolated line $(12 \mathrm{~nm})$. With these process conditions, denser lines are not perfectly developed due to proximity effects.
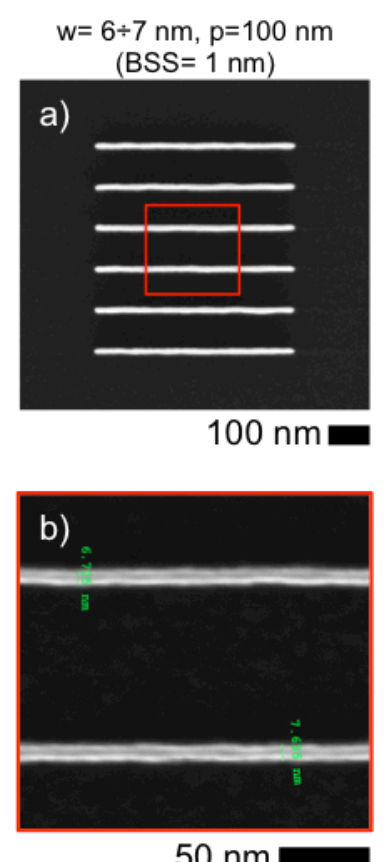

$50 \mathrm{~nm}$

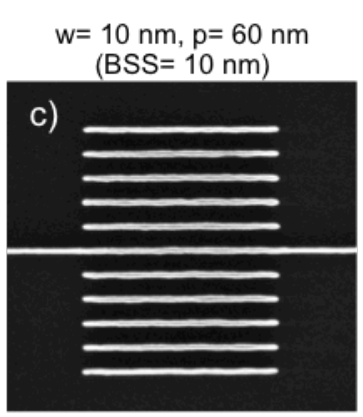

$\mathrm{w}=20 \mathrm{~nm}, \mathrm{p}=60 \mathrm{~nm}$ (BSS $=15 \mathrm{~nm}$ )

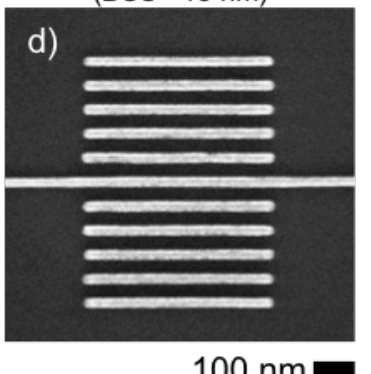

$100 \mathrm{~nm}$

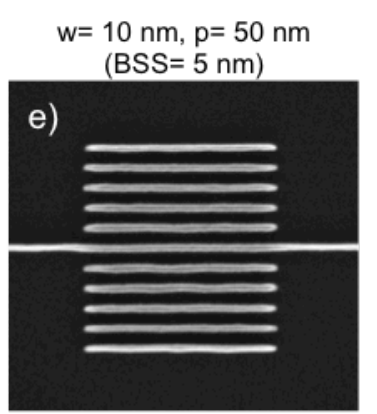

$\mathrm{w}=18 \mathrm{~nm}, \mathrm{p}=50 \mathrm{~nm}$ $(B S S=10 \mathrm{~nm})$

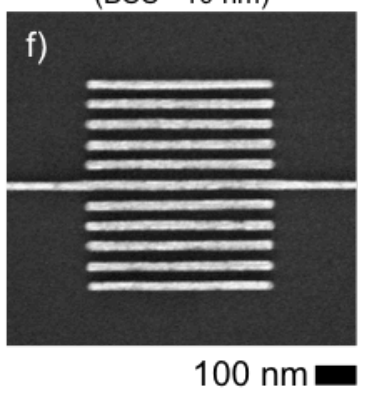

$\mathrm{w}=10 \mathrm{~nm}, \mathrm{p}=40 \mathrm{~nm}$ $(B S S=1 \mathrm{~nm})$

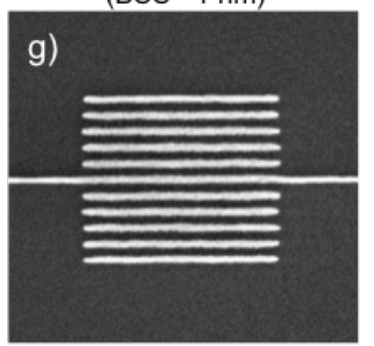

$w=12 / 15 \mathrm{~nm}, \mathrm{p}=40 \mathrm{~nm}$ (BSS $=10 \mathrm{~nm}$ )

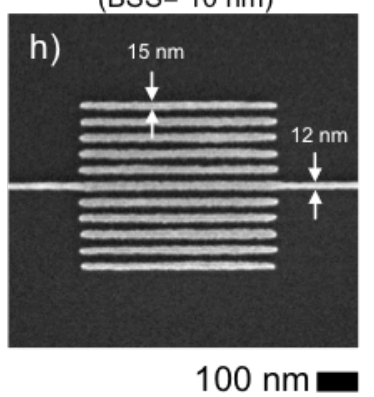

Figure 2 - SEM images of EBL exposed alumina resist. a-b) $6 \div 7 \mathrm{~nm}$ lines exposed with beam step size (BSS) $=1 \mathrm{~nm}$ and period $(\mathrm{p})$ $=100 \mathrm{~nm} . \mathrm{c}-\mathrm{d}) 10 \mathrm{~nm}(20 \mathrm{~nm})$ lines exposed with BSS $=1 \mathrm{~nm}(15 \mathrm{~nm})$ and $\mathrm{p}=60 \mathrm{~nm}$. e-f) $10 \mathrm{~nm}(18 \mathrm{~nm})$ lines exposed with BSS $=$ $5 \mathrm{~nm}(10 \mathrm{~nm}) \mathrm{p}=50 \mathrm{~nm}$. g-h) $12 / 15 \mathrm{~nm}$ lines exposed with $B S S=1 \mathrm{~nm}$ and $\mathrm{p}=40 \mathrm{~nm}$.

Figure 3 shows a series of SEM images of alumina resist lines at different pitches (isolated, p=62, 40 and $20 \mathrm{~nm}$ ) exposed by FHIB at $30 \mathrm{keV}$. Doses ranging from 200 and $700 \mu \mathrm{C} / \mathrm{cm}^{2}$ and BSS were adjusted to obtain the same linewidth for the isolated line and the lines in the array. In this case, resist thickness was $20 \mathrm{~nm}$ thick for all the pitches and was developed for $2 \mathrm{~min} 30 \mathrm{sec}$ at $21^{\circ} \mathrm{C}$ in $\mathrm{HCl}$ :IPA (2:100). As for EBL, isolated lines can be patterned at the sub-10 $\mathrm{nm}$ sale $(5 \mathrm{~nm})$. Remarkably, FHIB exposed lines seem to have reduced line edge roughness as compared to EBL 
exposed lines. FHIB exposure clearly shows lower proximity effects, and lines with a pitch down to $20 \mathrm{~nm}$ were perfectly developed. Also, line-width is constant for the isolated line and for the lines in the array.

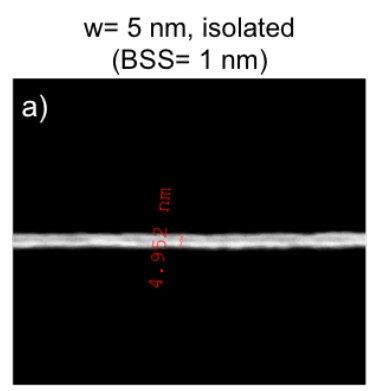

$50 \mathrm{~nm}$ $\mathrm{w}=20 \mathrm{~nm}, \mathrm{p}=64 \mathrm{~nm}$ $(\mathrm{BSS}=16 \mathrm{~nm})$

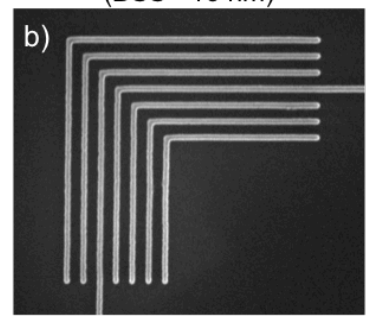

$200 \mathrm{~nm}$

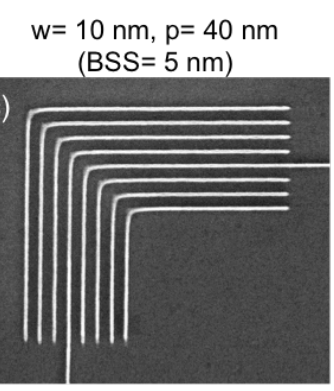

$100 \mathrm{~nm}$

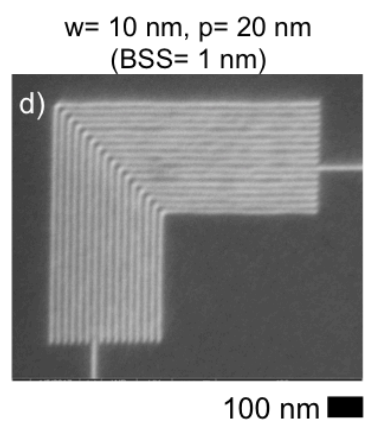

Figure 3 - SEM images of FHIB exposed alumina resist $(20 \mathrm{~nm}$ thick). a) $5 \mathrm{~nm}$ isolated line exposed with BSS $=1 \mathrm{~nm}$. b) $20 \mathrm{~nm}$ lines exposed with BSS $=16 \mathrm{~nm}$ and $\mathrm{p}=64 \mathrm{~nm}$. c) $10 \mathrm{~nm}$ lines exposed with BSS $=5 \mathrm{~nm}$ and $\mathrm{p}=40 \mathrm{~nm}$. d) $10 \mathrm{~nm}$ lines exposed with $\mathrm{BSS}=1 \mathrm{~nm}$ and $\mathrm{p}=20 \mathrm{~nm}$.

\subsection{Pattern transfer}

Grencia et $\mathrm{al}^{14}$ demonstrated exceptional selectivity (100:1) of the alumina resist when used as a mask for ICP etching of silicon in fluorinated plasmas. In this work, we opted for an RIE process to transfer the pattern in the silicon substrate. Silicon etching rates of conventional RIE processes are typically lower as compared to ICP processes so that, with RIE, the etched depth can be more precisely controlled. On the other hand, an RIE process is less versatile since the bias is imposed by the pressure/power/gas combination. Preliminary tests were carried out using a standard silicon etching process based on $\mathrm{SF}_{6} / \mathrm{CHF}_{3}$ normally used in combination with a Poly(methyl methacrylate) (PMMA) resist mask. Using this process, we obtained high line edge roughness and poor selectivity (not shown), likely due to the relatively high bias of the process $(200 \mathrm{~V})$. In this regard, it should be noted that the resist's strong selectivity stems from the fact that alumina in fluorine-containing plasmas leads to the formation of non-volatile compounds $\left(\mathrm{AlF}_{3}\right.$, for instance, sublimates at ca. $1250{ }^{\circ} \mathrm{C}$ ) and therefore etches extremely slowly. ${ }^{13}$ High biases result in strong mechanical ion bombardment of the resist thus losing its chemical selectivity. We obtained reduced bias of $80 \mathrm{~V}$ by lowering the power (to $8 \mathrm{~W}$ ), increasing the working pressure (to $15 \mathrm{mTorr}$ ), and reducing the $\mathrm{SF}_{6} / \mathrm{CHF}_{3}$ ratio (to $1: 2$ ).

Figure 4 shows SEM images of two examples of pattern transfer using the optimized RIE process at $80 \mathrm{~V}$ bias. The reduced bias improves selectivity and results in smooth surfaces. We obtained lines of 10 (20) nm width and 60 (50) $\mathrm{nm}$ pitch etched to a depth of 103 (64) nm, corresponding to an aspect ratio of 10 (3). Further optimization of the RIE process is required to improve the pattern transfer in denser lines (not shown), in particular the selectivity and the $\mathrm{SF}_{6} / \mathrm{CHF}_{3}$ ratio to further improve the verticality of the side-walls. 

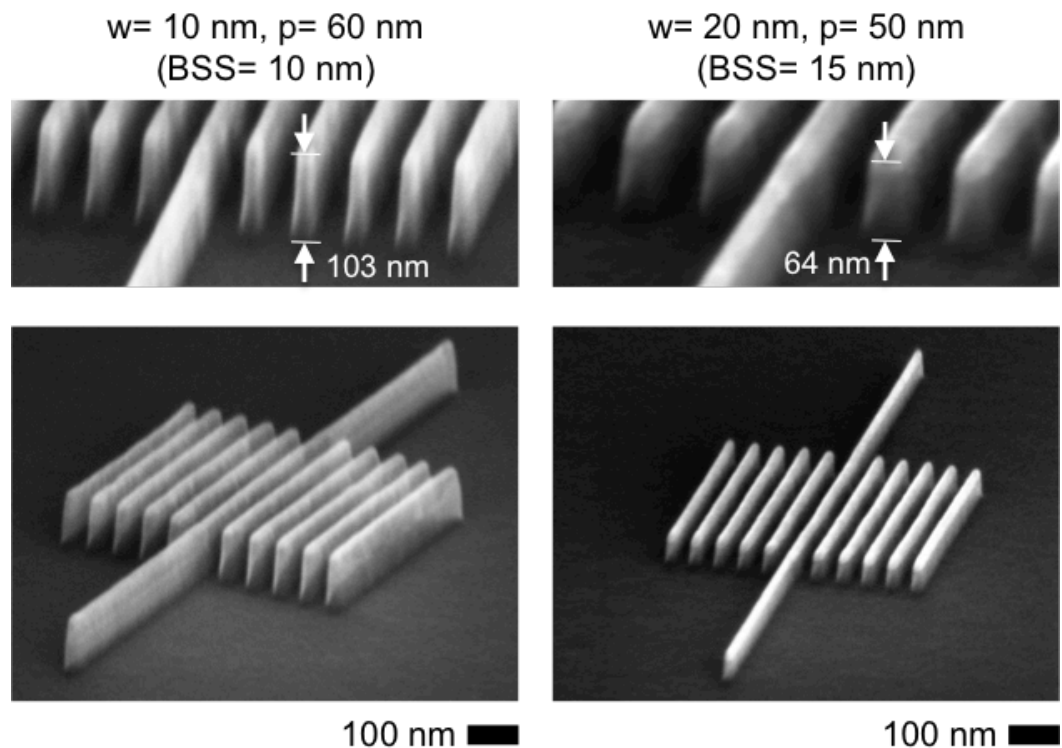

Figure 4 - SEM images of pattern transfer in silicon using $80 \mathrm{~V}$ bias RIE with two different etching times.

\section{Conclusions}

We present our preliminary results on the use of a spin-on alumina-based hybrid resist for EBL at $100 \mathrm{keV}$ and FHIB originally proposed by Zanchetta et al. ${ }^{13}$ Contrary to what Zanchetta et al. observed, we obtain perfectly flat and defect-free resist layers. Further investigation is needed to clarify whether this improvement was due to a lower RH of our clean room or to a beneficial effect on spin-coating deposition when less toxic (and less volatile) triethoxyphenylsilane is used instead of trimethoxyphenylsilane.

We show that the resist contrast curve can be strongly dependent on process parameters. While temperature development does not seem to affect resist contrast but only sensitivity, a delay between exposure and post-baking and/or development can dramatically modify the contrast curve. We interpret the double slope contrast curve obtained for delayed development as the result of a surface modification of the resist reacting in air and we show that post-baking treatment can mitigate this reaction. We also show how aging the resist solution affects the contrast curve.

Lastly, we demonstrate that the resist is suitable for lithography of sub-10 nm features, including isolated lines as small as $6.5 \mathrm{~nm}$ using EBL and $5 \mathrm{~nm}$ using FHIB. Perfect development of denser lines is limited to pitches of $40 \mathrm{~nm}$ for EBL due to proximity effects, but can be reduced to $20 \mathrm{~nm}$ when FHIB is used to expose the resist. We demonstrate the pattern transfer of $10 \mathrm{~nm}$ lines with an aspect ratio of 10 in silicon using a low bias reactive ion etching process.

This work demonstrates the great potential of such alumina-based resist (high resolution, low line edge roughness, exceptional selectivity) as well as its limitations in terms of stability, time window of the process, and resist solution lifetime. Precisely controlling these variables will be fundamental in order to further optimize other process parameters such as pre- and post-bake temperature, developer concentration, etc..

\section{Acknowledgements}

This research has been implemented and financially supported through EU's H2020 Framework Program, in project Nanoscience Foundries and Fine Analysis - Europe (NFFA-Europe), project number 654360. The work was also partially supported by the French RENATECH network. 
${ }^{1}$ X. Yang, S. Xiao, W. Wu, Y. Xu, , K. Mountfield, R. Rottmayer, K. Lee, D. Kuo, and D. Weller, J. Vac. Sci. Technol. B 25, 2202 (2007).

${ }^{2}$ Y. F. Chen, H. F. Yang, and Z. Cui, Microelectron. Eng. 83, 1119 (2006).

${ }^{3}$ M. Haffner, A. Heeren, M. Fleischer, D. P. Kern, G. Schmidt, and L. W. Molenkamp, Microelectron. Eng. 84, 937 (2007).

${ }^{4}$ Sidorkin, E. van der Drift, and H. Salemink, J. Vac. Sci. Technol. B 26, 2049 (2008).

${ }_{6}^{5}$ A. E. Grigorescu, M. C. van der Krogt, C. W. Hagen, and P. Kruit, Microelectron. Eng. 84, 822 (2007).

${ }^{6}$ A. Cattoni, E. Cambril, D. Decanini, G. Faini, A.M. Haghiri-Gosnet, Microelectronic Engineering 87 1015-1018 (2010).

${ }^{7}$ J. K. W. Yang, B. Cord, H. Duan, K. K. Berggren, J. Klingfus, S.-W. Nam, K.-B. Kim, M. J. Rooks, J. Vac. Sci. Technol. B 272622 (2009).

${ }^{8}$ V. Sidorkin, E. van Veldhoven, E. van der Drift, P. Alkemade, H. Salemink, D. Maas, J. Vac. Sci. Technol. B 27, L18 (2009).

${ }^{9}$ D. Winston and B. M. Cord, B. Ming, D. C. Bell, W. F. DiNatale and L. A. Stern, A. E. Vladar and M. T. Postek, M. K. Mondol, J. K. W. Yang, and K. K. Berggren, J. Vac. Sci. Technol. B 27, 2702 (2009).

${ }^{10}$ W.-D. Li, W. Wu, R. S. Williams, J. Vac. Sci. Technol. B 30, 06F304-1 (2012).

${ }^{11}$ C. Popescu, A. McClelland, G. Dawson, J. Roth, D. Kazazis, Y. Ekinci, W. Theis, A. P. G. Robinson, Proc. SPIE 10446, 33rd European Mask and Lithography Conference, 1044608 (2017).

${ }^{12}$ S. Takei, N. Sugino, M. Hanabata, A. Oshima, M. Kashiwakura, T. Kozawa, S. Tagawa, Applied Physics Express 10, 076502 (2017).

${ }^{13}$ E. Zanchetta, G. Della Giustina, G. Grenci, A. Pozzato, M. Tormen, G. Brusatin, Adv. Mater. 25, 6261 (2013).

${ }^{14}$ G. Grencia, E. Zanchetta, A. Pozzato, G. Della Giustina, G. Brusatin, M. Tormena, Applied Materials Today 1, 13 (2015). 